\title{
Identification of positron emission tomography (PET) tracer candidates by prediction of the target-bound fraction in the brain
}

\author{
Markus Fridén ${ }^{1,2}$, Marie Wennerberg ${ }^{3}$, Madeleine Antonsson $^{3}$, Maria Sandberg-Ställ ${ }^{4}$, Lars Farde ${ }^{5}$ and Magnus Schou ${ }^{5^{*}}$
}

\begin{abstract}
Background: Development of tracers for imaging with positron emission tomography (PET) is often a time-consuming process associated with considerable attrition. In an effort to simplify this process, we herein propose a mechanistically integrated approach for the selection of tracer candidates based on in vitro measurements of ligand affinity $\left(K_{d}\right)$, non-specific binding in brain tissue $\left(V_{u, b r a i n}\right)$, and target protein expression $\left(B_{\max }\right)$.

Methods: A dataset of 35 functional and 12 non-functional central nervous system (CNS) PET tracers was compiled. Data was identified in literature for $\mathrm{K}_{d}$ and $\mathrm{B}_{\max }$ whereas a brain slice methodology was used to determine values for $V_{u, b r a i n}$. A mathematical prediction model for the target-bound fraction of tracer in the brain $\left(f_{t b}\right)$ was derived and evaluated with respect to how well it predicts tracer functionality compared to traditional PET tracer candidate selection criteria.
\end{abstract}

Results: The methodology correctly classified 31/35 functioning and 12/12 non-functioning tracers. This predictivity was superior to traditional classification criteria or combinations thereof.

Conclusions: The presented CNS PET tracer identification approach is rapid and accurate and is expected to facilitate the development of novel PET tracers for the molecular imaging community.

Keywords: Positron emission tomography; Non-specific binding; Imaging; Receptor occupancy

\section{Background}

Positron emission tomography (PET) is a molecular imaging technique that is being increasingly used in medical research and drug development. The non-invasive nature of PET, the low chemical mass of the radiolabeled probe used in the emission measurement (usually only micrograms), and the relatively low radiation burden associated with a PET measurement have positioned PET as one of the key enabling technologies in translational medicine. PET can be applied for a wide range of purposes, but all are crucially dependent on the availability of suitable radiotracers for the emission measurements.

The development of PET tracers for the central nervous system (CNS) is often a time-consuming process associated with considerable attrition. Thus, despite the plethora

\footnotetext{
* Correspondence: magnus.schou@astrazeneca.com

${ }^{5}$ AstraZeneca Translational Science Centre, Department of Clinical

Neuroscience, Karolinska Institutet, Stockholm, Sweden

Full list of author information is available at the end of the article
}

of novel targets of interest for PET imaging, the availability of useful tracers constitutes a bottleneck in nuclear medicine and drug industry. The high attrition rate in tracer development can be attributed to the many properties that a successful CNS tracer has to satisfy including tracer affinity, non-specific binding, blood-brain barrier transport, metabolic stability, etc. (Figure 1) [1-5].

Over the years, considerable efforts have been directed to the development of methods for selection of CNS PET tracer candidates. In particular, the prediction of nonspecific brain tissue binding has been in focus, for which in silico, in vitro, or bio-mathematical methods have been applied [6-9]. Recently, a selection method comprising the composite of weighted physicochemical parameters (CNS PET multiparameter optimization or 'MPO'), free fractions in plasma and the brain, as well as membrane permeability has been reported [10].

The aim of the present work was to develop and examine an integrated model for identification of promising CNS 


\begin{tabular}{ll}
\hline \multicolumn{1}{c}{ Variable } & \multicolumn{1}{c}{ Criterion } \\
\hline Structure & $\begin{array}{l}\text { Suitable for radiolabeling with a positron emitting } \\
\text { radionuclide. }\end{array}$ \\
$\begin{array}{l}\text { In vitro affinity } \\
\text { Dissociation constant }\left(\mathrm{K}_{\mathrm{d}}\right) \text { in the nanomolar or sub- } \\
\text { nanomolar range. Rule of thumb: } \mathrm{B}_{\text {max }} / \mathrm{K}_{\mathrm{d}} \geq 10 .\end{array}$ \\
$\begin{array}{l}\text { In vitro } \\
\text { selectivity }\end{array}$ & High selectivity required for specific imaging. \\
$\begin{array}{l}\text { Non-specific } \\
\text { binding }\end{array}$ & $\begin{array}{l}\text { Low non-specific binding enables more sensitive imaging. } \\
\text { Rule of thumb: Log } \mathrm{P} \text { or Log } \mathrm{D}_{7.4}<3 .\end{array}$ \\
Brain exposure & Adequate for brain imaging, Rule of thumb: $1 \leq$ Log $\mathrm{D}_{7.4} \leq 3$. \\
Metabolism & $\begin{array}{l}\text { Parent tracer constitutes the main radiochemical entity in } \\
\text { brain. }\end{array}$ \\
\hline Toxicity & Safe for administration in tracer doses. \\
\hline
\end{tabular}

Figure 1 Commonly applied criteria for CNS candidate tracer selection.

tracer candidates. The model includes only estimates of non-specific binding, tracer affinity, and target protein expression in the brain. The outcome parameter is the target-bound fraction of tracer in the brain $\left(f_{t b}\right)$. The model was validated on a set of 47 successful or failed tracer developments.

\section{Methods}

\section{CNS PET tracer dataset}

A CNS PET tracer dataset was generated by compilation of 31 PET tracers that either have been evaluated in house at the PET centre at Karolinska Institutet, Sweden, or are related to targets that have been examined at the PET centre. Complementing this dataset, a subset of 18 tracers with measured unbound fraction in brain homogenate was included from a recently published CNS PET tracer database [10]. Tracers were classified as functional or non-functional based on their utility in vivo for reliable quantification of specific target binding. Two tracer molecules were excluded from the dataset: $\left[{ }^{11} \mathrm{C}\right]$ GSK215083 due to insufficient selectivity and $\left[{ }^{11} \mathrm{C}\right]$ RWAY due to radioactive metabolites that potentially confounded PET images. The final dataset comprised 35 validated functioning PET tracers and 12 non-functioning tracers (Table 1).

For each tracer, target density $\left(\mathrm{B}_{\max }\right)$, the affinity $\left(\mathrm{K}_{\mathrm{d}}\right)$ of the tracer for the target, and the non-displaceable binding potential $\left(\mathrm{BP}_{\mathrm{ND}}\right)$ were obtained from the literature. A single value of $K_{d}$ was entered into the database even if more than one value has been reported in literature. Selection preference was given to (1) reports containing data from human material, (2) reports containing data on both $\mathrm{K}_{\mathrm{d}}, \mathrm{B}_{\max }$, or $\mathrm{BP}_{\mathrm{ND}}$, or (3) the first encountered report.
The unbound volume of distribution in the brain $\left(\mathrm{V}_{\mathrm{u} \text {,brain }}\right)$ describing the extent of non-specific partitioning was determined for 31 tracers using a previously described high-throughput brain slice method [11]. Compound material was not available for 16 tracers and $V_{u \text {,brain }}$ was instead calculated from reported measurements of unbound fraction in homogenized brain tissue and the tracer $\mathrm{pK}_{\mathrm{a}}$ using a $\mathrm{pH}$-partition model [12]. Molecular descriptors including ClogP, ACDlogD7.4, polar surface area (PSA), molecular weight (MW), hydrogen bond donor count (HBD), and $\mathrm{ACDpK}_{\mathrm{a}}$ were calculated and used to generate the CNS PET multiparameter optimization (MPO) score [10]. An extended version of Table 1 with complete literature references is provided as supplementary material and includes the calculated molecular properties (Additional file 1).

\section{Equations and relationships}

A mathematical relationship for $f_{t b}$ was derived from a model of the total concentration of tracer in brain tissue $\left(\mathrm{C}_{\text {brain }}, \mathrm{pmol} / \mathrm{g}\right.$ brain) comprising non-specific tracer and target-bound tracer. The concentration of non-specific tracer is determined by the product of $\mathrm{V}_{\mathrm{u}, \text { brain }}(\mathrm{mL} / \mathrm{g}$ brain) and the unbound tracer concentration in the brain interstitial fluid $\left(\mathrm{C}_{\mathrm{u} \text {,brainISF, }} \mathrm{nmol} / \mathrm{L}\right.$ ISF). The concentration of target-bound tracer is described by a nonlinear expression with $C_{u \text {,brainISF, }} K_{d}(n m o l / L)$, and $B_{\max }$ (nmol/g brain) (Eq. 1).

$$
C_{\text {brain }}=C_{\mathrm{u}, \text { brainISF }} \times V_{\mathrm{u} \text {,brain }}+\frac{B_{\max } \times C_{\mathrm{u}, \text { brainISF }}}{C_{\mathrm{u}, \text { brainISF }}+K_{d}}
$$

The relative proportion of the specific binding term in $\mathrm{C}_{\text {brain }}$, i.e. the target-bound fraction $\left(\mathrm{f}_{\mathrm{tb}}\right)$, is derived from 
Table 1 CNS PET tracer dataset ${ }^{a}$

\begin{tabular}{|c|c|c|c|c|c|c|c|c|}
\hline & & \multirow[t]{2}{*}{ Target } & \multicolumn{4}{|c|}{ In vitro data } & \multicolumn{2}{|c|}{ PET data } \\
\hline & & & $\begin{array}{l}B_{\max } \\
(n M)^{b}\end{array}$ & $\begin{array}{l}K_{d} \\
(n M)\end{array}$ & $\begin{array}{l}\mathrm{V}_{\mathrm{u}, \text { brain }} \\
\text { (mL/g brain) }\end{array}$ & $f_{t b}$ & $\mathrm{BP}_{\mathrm{ND}}$ & $f_{\mathrm{tb}}$ \\
\hline$\left[{ }^{18} \mathrm{~F}\right] 2-\mathrm{FA}-85380$ & Yes & nAChr a4b2 & 0.7 & 0.145 & 1.7 & 0.74 & 1.8 & 0.64 \\
\hline$\left[{ }^{11} \mathrm{C}\right] \mathrm{AFM}$ & Yes & SERT & 38 & 1.04 & 46 & 0.44 & 1.4 & 0.58 \\
\hline$\left[{ }^{18} \mathrm{~F}\right]$ Altanserin & Yes & $5 \mathrm{HT} 2 \mathrm{a}$ & 89 & 0.32 & 122 & 0.70 & 1.06 & 0.51 \\
\hline$\left[{ }^{11} \mathrm{C}\right] \mathrm{AZ} 10419369$ & Yes & $5 \mathrm{HT} 1 \mathrm{~b}$ & $9.8^{c}$ & 0.37 & 30 & 0.47 & 1.3 & 0.57 \\
\hline$\left[{ }^{11} \mathrm{C}\right] \mathrm{AZD} 2184$ & Yes & Amyloid & 1,407 & 4.9 & 33 & 0.90 & 1.1 & 0.52 \\
\hline$\left[{ }^{11} \mathrm{C}\right] \mathrm{AZD} 2995$ & Yes & Amyloid & 1,407 & 6.2 & 7 & 0.97 & 0.6 & 0.38 \\
\hline$\left[{ }^{18} \mathrm{~F}\right] \mathrm{AZD} 4694$ & Yes & Amyloid & 1,407 & 2.3 & 205 & 0.75 & 1.2 & 0.55 \\
\hline$\left[{ }^{11} \mathrm{C}\right] \mathrm{CP}-126998$ & Yes & AchE & 211 & 0.48 & 41 & 0.92 & & \\
\hline$\left[{ }^{11} \mathrm{C}\right] \mathrm{DASB}$ & Yes & SERT & 38 & 3.5 & 31 & 0.26 & 1.6 & 0.62 \\
\hline$\left[{ }^{18}\right.$ F]Fallypride ${ }^{f}$ & Yes & D2 & 27 & 0.03 & 18 & 0.98 & 22.2 & 0.96 \\
\hline$\left[{ }^{18}\right.$ F]Fallypride ${ }^{9}$ & Yes & D2 & 0.9 & 0.03 & 18 & 0.63 & 2.11 & 0.68 \\
\hline$\left[{ }^{18} \mathrm{~F}\right] \mathrm{FE}-\mathrm{PE} 2 \mathrm{I}$ & Yes & DAT & 212 & 12 & 62 & 0.22 & 4.1 & 0.80 \\
\hline$\left[{ }^{18} \mathrm{~F}\right] \mathrm{FEPPA}[\mathrm{iv}]$ & Yes & TSPO & 58 & 0.07 & 15 & 0.98 & 4.4 & 0.81 \\
\hline$\left[{ }^{11} \mathrm{C}\right] \mathrm{FLB} 457$ & Yes & D2 & 0.9 & 0.02 & 26 & 0.63 & 2.6 & 0.72 \\
\hline$\left[{ }^{11} \mathrm{C}\right]$ Flumazenil & Yes & GABA & 71 & 0.7 & 3.2 & 0.97 & 5.8 & 0.85 \\
\hline$\left[{ }^{18} \mathrm{~F}\right] \mathrm{FP}-\mathrm{CIT}$ & Yes & DAT & 212 & 33 & 36 & 0.15 & 1.0 & 0.50 \\
\hline$\left[{ }^{11} \mathrm{C}\right] \mathrm{GR} 103545$ & Yes & KOR & $3.75^{\mathrm{c}}$ & 0.048 & 41 & 0.66 & 2.18 & 0.69 \\
\hline$\left[{ }^{11} \mathrm{C}\right] \mathrm{GR} 205171$ & Yes & NK1 & 55 & 0.016 & 57 & 0.98 & 14.5 & 0.94 \\
\hline$\left[{ }^{11} \mathrm{C}\right] \mathrm{GSK} 189254 \mathrm{~A}$ & Yes & $\mathrm{H} 3$ & 8.4 & 0.08 & 8.5 & 0.93 & 1.3 & 0.57 \\
\hline$\left[{ }^{11} \mathrm{C}\right]$ Harmine & Yes & MAO-A & 270 & 5 & 25 & 0.68 & 1.7 & 0.63 \\
\hline$\left[{ }^{11} \mathrm{C}\right] \mathrm{MADAM}$ & Yes & SERT & 38 & 0.06 & 90 & 0.88 & 1.4 & 0.58 \\
\hline$\left[{ }^{11} \mathrm{C}\right] \mathrm{McN} 5652$ & Yes & SERT & 38 & 0.2 & 238 & 0.44 & 0.50 & 0.33 \\
\hline$\left[{ }^{11} \mathrm{C}\right] \mathrm{MDL} 100907$ & Yes & $5 \mathrm{HT} 2 \mathrm{a}$ & 89 & 0.24 & 17 & 0.96 & 1.3 & 0.57 \\
\hline$\left[{ }^{11} \mathrm{C}\right] \mathrm{MePPEP}$ & Yes & CB1r & 47 & 0.1 & 296 & 0.61 & 5.5 & 0.85 \\
\hline$\left[{ }^{18} \mathrm{~F}\right] \mathrm{MPPF}$ & Yes & $5 \mathrm{HT} 1 \mathrm{a}$ & 350 & 3.3 & 14 & 0.89 & 1.6 & 0.62 \\
\hline$\left[{ }^{11} \mathrm{C}\right] \mathrm{NNC} 112$ & Yes & D1 & 93 & 0.18 & 70 & 0.88 & 2.85 & 0.74 \\
\hline$\left[{ }^{11} \mathrm{C}\right] \mathrm{PBR} 28$ & Yes & TSPO & 58 & 1.8 & 11 & 0.75 & 3.99 & 0.80 \\
\hline$\left[{ }^{11} \mathrm{C}\right] \mathrm{PE} 2 \mathrm{l}$ & Yes & DAT & 212 & 4.9 & 39 & 0.53 & 8.0 & 0.89 \\
\hline$\left[{ }^{11} \mathrm{C}\right] \mathrm{PHNO}$ & Yes & D2/D3 & $26.5^{d}$ & 0.56 & 11 & 0.81 & 2.5 & 0.71 \\
\hline$\left[{ }^{11} \mathrm{C}\right] \mathrm{PIB}$ & Yes & Amyloid & 1,407 & 2.5 & 250 & 0.69 & 0.85 & 0.46 \\
\hline$\left[{ }^{11} \mathrm{C}\right] \mathrm{PK} 11195$ & Yes & TSPO & 58 & 4.3 & 59 & 0.19 & 0.18 & 0.15 \\
\hline$\left[{ }^{11} \mathrm{C}\right]$ Raclopride & Yes & D2 & 27 & 2.5 & 9.4 & 0.53 & 2.6 & 0.72 \\
\hline$\left[{ }^{18} \mathrm{~F}\right]$ Spiperone & Yes & D2 & 27 & 0.028 & 147 & 0.87 & & \\
\hline$\left[{ }^{11} \mathrm{C}\right] \mathrm{SB} 207145$ & Yes & $5 \mathrm{HT} 4$ & 21 & 0.037 & 4.4 & 0.99 & 3.4 & 0.77 \\
\hline$\left[{ }^{11} \mathrm{C}\right] \mathrm{SCH} 23390$ & Yes & D1 & 93 & 2.1 & 32 & 0.58 & 1.8 & 0.64 \\
\hline$\left[{ }^{11} \mathrm{C}\right] \mathrm{WAY} 100635$ & Yes & $5 \mathrm{HT} 1 \mathrm{a}$ & 350 & 1.1 & 14 & 0.96 & 7.4 & 0.88 \\
\hline$\left[{ }^{11} \mathrm{C}\right]$ Citalopram & No & SERT & 38 & 4.8 & 60 & 0.12 & 0.1 & 0.09 \\
\hline$\left[{ }^{11} \mathrm{C}\right]$ Clomipramine & No & SERT & 38 & 0.15 & 863 & 0.23 & 0.1 & 0.09 \\
\hline$\left[{ }^{11} \mathrm{C}\right] \mathrm{CPEB}[\mathrm{iv}]$ & No & ORL-1 & $13.5^{\mathrm{e}}$ & 1.1 & 143 & 0.08 & 0.1 & 0.09 \\
\hline$\left[{ }^{11} \mathrm{C}\right]$ Desipramine & No & NET & 5 & 0.63 & 264 & 0.03 & 0.1 & 0.09 \\
\hline$\left[{ }^{11} \mathrm{C}\right]$ Diazepam & No & GABA & 71 & 7 & 20 & 0.34 & 0.1 & 0.09 \\
\hline$\left[{ }^{11} \mathrm{C}\right] \mathrm{MeNER}$ & No & NET & $5^{c}$ & 2.5 & 31 & 0.06 & 0.3 & 0.23 \\
\hline
\end{tabular}


Table 1 CNS PET tracer dataset ${ }^{\mathrm{a}}$ (Continued)

\begin{tabular}{llllllll}
\hline$\left[{ }^{11} \mathrm{C}\right]$ NE100 & No & Sigma & $23^{\mathrm{e}}$ & 1.2 & 96 & 0.17 & 0.1 \\
{$\left[{ }^{11} \mathrm{C}\right]$ Nisoxetine } & No & NET & 5 & 0.73 & 58 & 0.11 & 0.1 \\
{$\left[{ }^{18} \mathrm{~F}\right]$ Paroxetine } & No & SERT & 38 & 0.065 & 876 & 0.10 & 0.1 \\
{$\left[{ }^{11} \mathrm{C}\right]$ Remoxipride } & No & D2 & 27 & 270 & 6.3 & 0.09 & 0.1 \\
{$\left[{ }^{11} \mathrm{C}\right]$ Sertraline } & No & SERT & 38 & 0.15 & 4,184 & 0.09 & 0.09 \\
{$\left[{ }^{11} \mathrm{C}\right]$ Venlafaxine } & No & SERT & 38 & 7.5 & 10 & 0.1 & 0.09 \\
\hline
\end{tabular}

${ }^{a}$ An extended version of this table is provided as supporting information (Additional file 1: Table S1), which includes literature references to $B_{\text {max }}, K_{d}$, and $B_{\text {ND }}$ for each tracer, details of $\mathrm{V}_{\mathrm{u}, \text { brain }}$ determination, calculated molecular descriptors and CNS PET MPO score, and the region of brain tissue interest.

${ }^{b}$ Data refers to human brain tissue unless otherwise specified.

'Monkey.

${ }^{\mathrm{d}}$ Dog.

${ }^{\text {eRat. }}$

${ }^{f} B_{\max }$ value refers to caudate.

${ }^{\mathrm{g}} \mathrm{B}_{\max }$ value refers to thalamus.

Eq. 1 (Eq. 2) and simplifies under the conditions of $\mathrm{C}_{\mathrm{u}, \text { brainISF }}<<\mathrm{K}_{\mathrm{d}}$ (Eq. 3).

$$
\begin{aligned}
& f_{\mathrm{tb}}=\frac{1}{1+\frac{V_{\mathrm{u}, \mathrm{brain}} \times\left(K_{d}+C_{\mathrm{u}, \mathrm{brain} I \mathrm{SF}}\right)}{B_{\text {max }}}} \\
& f_{\mathrm{tb}}=\frac{1}{1+\frac{V_{\mathrm{u}, \text { brain }} \times K_{d}}{B_{\max }}}
\end{aligned}
$$

It is seen from Eq. 2 that the value of $\mathrm{f}_{\mathrm{tb}}(1)$ increases with increasing target density, (2) decreases with increasing non-specific binding $\left(\mathrm{V}_{\mathrm{u}, \text { brain }}\right)$, and (3) increases with increasing affinity to the target protein $\left(\mathrm{K}_{\mathrm{d}}\right)$. As illustrated in Figure 2, $\mathrm{f}_{\mathrm{tb}}$ is additionally dependent on $\mathrm{C}_{\mathrm{u} \text {,brainISF }}$ and has a plateau maximum value at infinitesimally low concentrations of tracer.

To facilitate comparison of in vitro predictions of $\mathrm{f}_{\mathrm{tb}}$ and in vivo PET studies, a relationship (Eq. 4) was

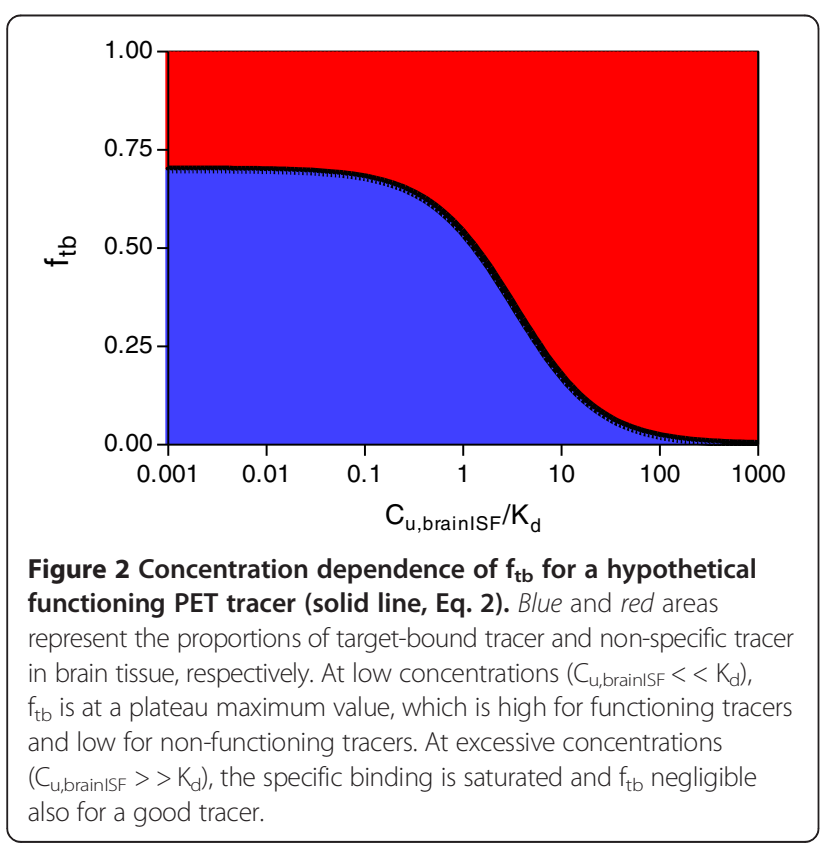

established with $\mathrm{BP}_{\mathrm{ND}}$, which is essentially the ratio of $B_{\max }$ and the $K_{d} \times V_{u \text {,brain }}$ product [13].

$$
f_{\mathrm{tb}}=\frac{\mathrm{BP}_{\mathrm{ND}}}{1+\mathrm{BP}_{\mathrm{ND}}}
$$

While the relationships described above follows the terminology used to describe pharmacokinetics of drug transport across the blood-brain barrier and distribution within the brain tissue [14], it is consistent with our previous work using PET nomenclature [13,15]. A derivation of Eq. 1 from PET nomenclature is provided as supplementary information (Additional file 2), as is a template spreadsheet for calculation of $\mathrm{f}_{\mathrm{tb}}$ (Additional file 3).

\section{The brain slice method}

The $V_{u, b r a i n}$ values for all available tracers were determined using a high-throughput brain slice method exactly as described previously [11], employing tracer analysis by liquid chromatography tandem mass spectrometry (LCMS/MS). The studies were approved by the Animal Ethics Committee of Gothenburg (234-2011).

\section{Results}

Table 1 presents the literature data of $K_{d}$ and $B_{\max }$ for each tracer and target along with the values of $\mathrm{V}_{\mathrm{u} \text {,brain }}$ determined in rat brain slices or calculated from reported data of binding in brain homogenate $\left(f_{u, b r a i n}\right)$. The dataset contained observations that span 3-4 orders of magnitude for each entity; the highest and lowest target expression level in the dataset was 1,407 and $0.2 \mathrm{nM}$ for amyloid $\beta$ protein aggregates and the nicotinic acetylcholine receptor respectively; the tracer affinities for their targets ranged from 0.016 to $270 \mathrm{nM}$ for GR205171 and Remoxipride, respectively, and in terms of nonspecific binding sertraline had the highest $\mathrm{V}_{\mathrm{u} \text {,brain }}$ value $\left(4,200 \mathrm{~mL} \cdot \mathrm{g}\right.$ brain $\left.^{-1}\right)$ and 2-FA-85380 the lowest $\left(1.7 \mathrm{~mL} \cdot \mathrm{g}\right.$ brain $\left.^{-1}\right)$. 
The target-bound fraction of tracer $\left(\mathrm{f}_{\mathrm{tb}}\right)$ could be derived from in vivo PET data for 33 of 35 functioning tracers but not for 11/12 non-functional tracers for which an arbitrary low value (0.09) was assigned (Table 1$)$. The values of $\mathrm{f}_{\mathrm{tb}}$ ranged from for very low $(<0.1)$ for most non-functioning tracers to 0.96 for $\left[{ }^{11} \mathrm{C}\right]$ Fallypride. In vitro predictions of $\mathrm{f}_{\mathrm{tb}}$, based on the brain slice method and literature data (Eq. 3), displayed a range of values from 0.02 for $\left[{ }^{11} \mathrm{C}\right]$ Remoxipride to 0.99 for $\left[{ }^{11} \mathrm{C}\right]$ Fallypride (Table 1). In general, tracers with predicted high $\mathrm{f}_{\mathrm{tb}}$ values had higher observed PET values for $\mathrm{f}_{\mathrm{tb}}$ than did tracers with low or moderate predicted $\mathrm{f}_{\mathrm{tb}}$ values (Figure 3 ). A cutoff value of 0.4 for $\mathrm{f}_{\mathrm{tb}}$ was used to correctly classify $31 / 35$ functioning tracers ( $89 \%$ sensitivity) and $12 / 12$ non-functioning tracers (100\% specificity).

Classification accuracy was determined also for the traditional CNS PET tracer selection criteria (Figure 1) and illustrated in Figure 4. Second to the presented $\mathrm{f}_{\mathrm{tb}}$ classification, which correctly classified all of the non-functioning tracers, was the $\mathrm{V}_{\mathrm{u} \text {,brain }}$ criterion $\left(\mathrm{V}_{\mathrm{u} \text {,brain }}\right.$ $\leq 20 \mathrm{~mL} \cdot \mathrm{g} \mathrm{brain}^{-1}$ ) resulting in $10 / 12$ correct classifications. This $\mathrm{V}_{\mathrm{u} \text {,brain }}$ criterion, however, only classified 13/35 functional tracers correctly. With respect to functioning tracers, $\mathrm{f}_{\mathrm{tb}}$ predictions were superseded by the $\mathrm{B}_{\max } / \mathrm{K}_{\mathrm{d}}$ criterion $\left(\mathrm{B}_{\max } / \mathrm{K}_{\mathrm{d}} \geq 10\right)$; however, $\mathrm{B}_{\max } / \mathrm{K}_{\mathrm{d}}$ classified correctly only $6 / 12$ non-functioning tracers. When combining the classification of both functional and nonfunctional tracers, $\mathrm{f}_{\mathrm{tb}}$ prediction resulted in $43 / 47$ (91\%) correct classifications followed by the $\mathrm{B}_{\max } / \mathrm{K}_{\mathrm{d}}$ criterion giving 39/47 (83\%) correct classifications. The MPO score, which does not rely on experimental data, made a total of $28 / 47$ correct classifications. A poor overall rate (23/47) of correct classification was observed for the logD-based criterion, which was originally conceived with the intention to limit non-specific tissue binding while allowing a certain degree of lipophilicity to have sufficient brain exposure. To test the capability of $\log \mathrm{D}$ to predict non-specific binding, a comparison of ACDLogD7.4 and $\mathrm{V}_{\mathrm{u} \text {,brain }}$ was made and illustrated in Figure 5.

\section{Discussion}

This study presents a mechanistically integrated approach for effective identification of PET tracer candidates based on simple and well-established theory. A prediction of the target-bound fraction of tracer $\left(\mathrm{f}_{\mathrm{tb}}\right)$ was made from measurements of target affinity, density, and the non-specific binding of the tracer measured in brain slices. The results show that a cutoff value of 0.4 for $\mathrm{f}_{\mathrm{tb}}$ can be used to correctly classify $91 \%$ of tracer candidates as either being functioning or non-functioning. Hence, a predicted $f_{t b}$ value greater than 0.4 can be seen as strong support to proceed with the development of a PET tracer, and a low value $(<0.4)$ indicates small chances of success.

While keeping in mind that the aim of predicting $\mathrm{f}_{\mathrm{tb}}$ is to improve decision making in the selection of PET-tracer candidates, a discussion is warranted on the agreement

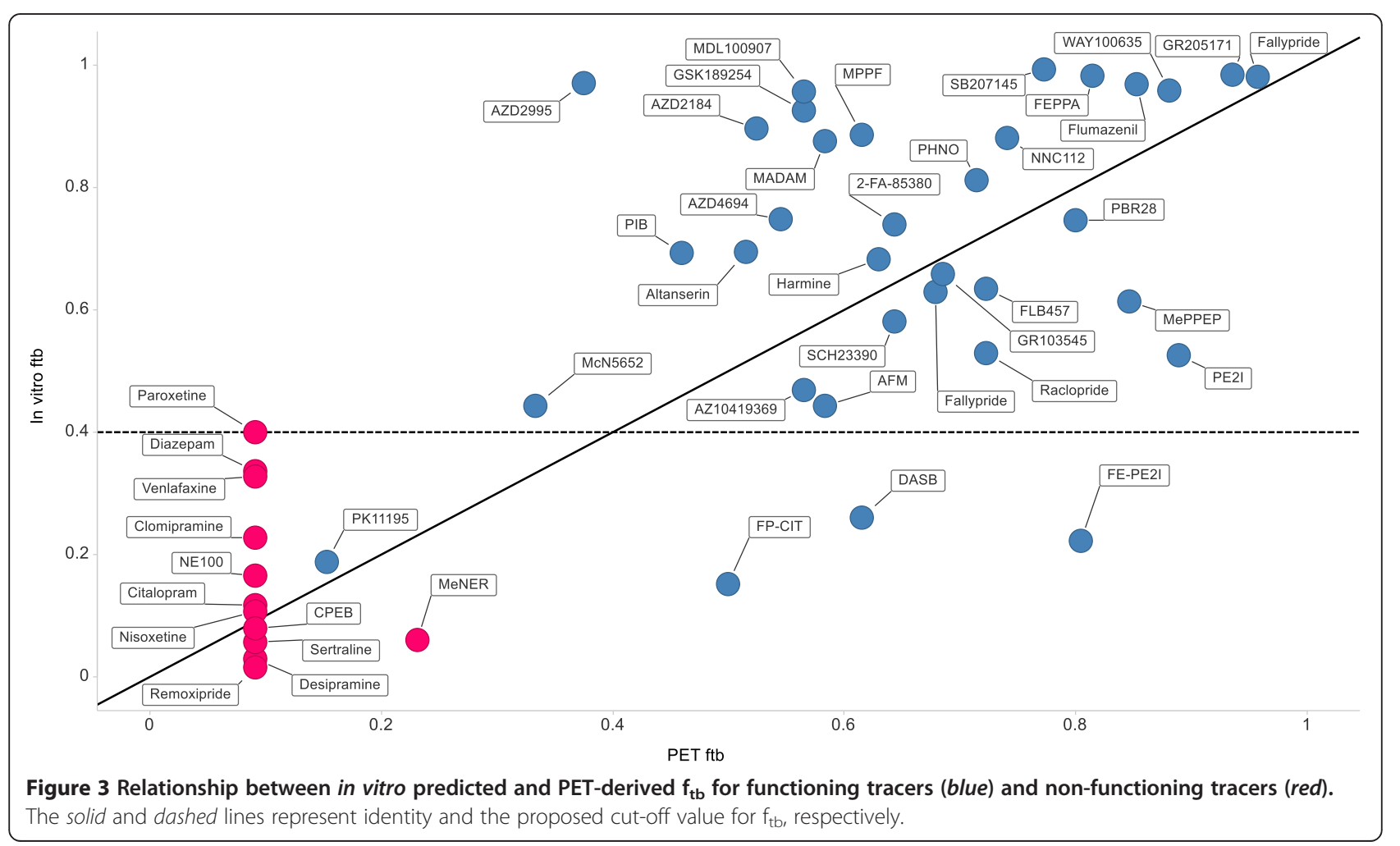




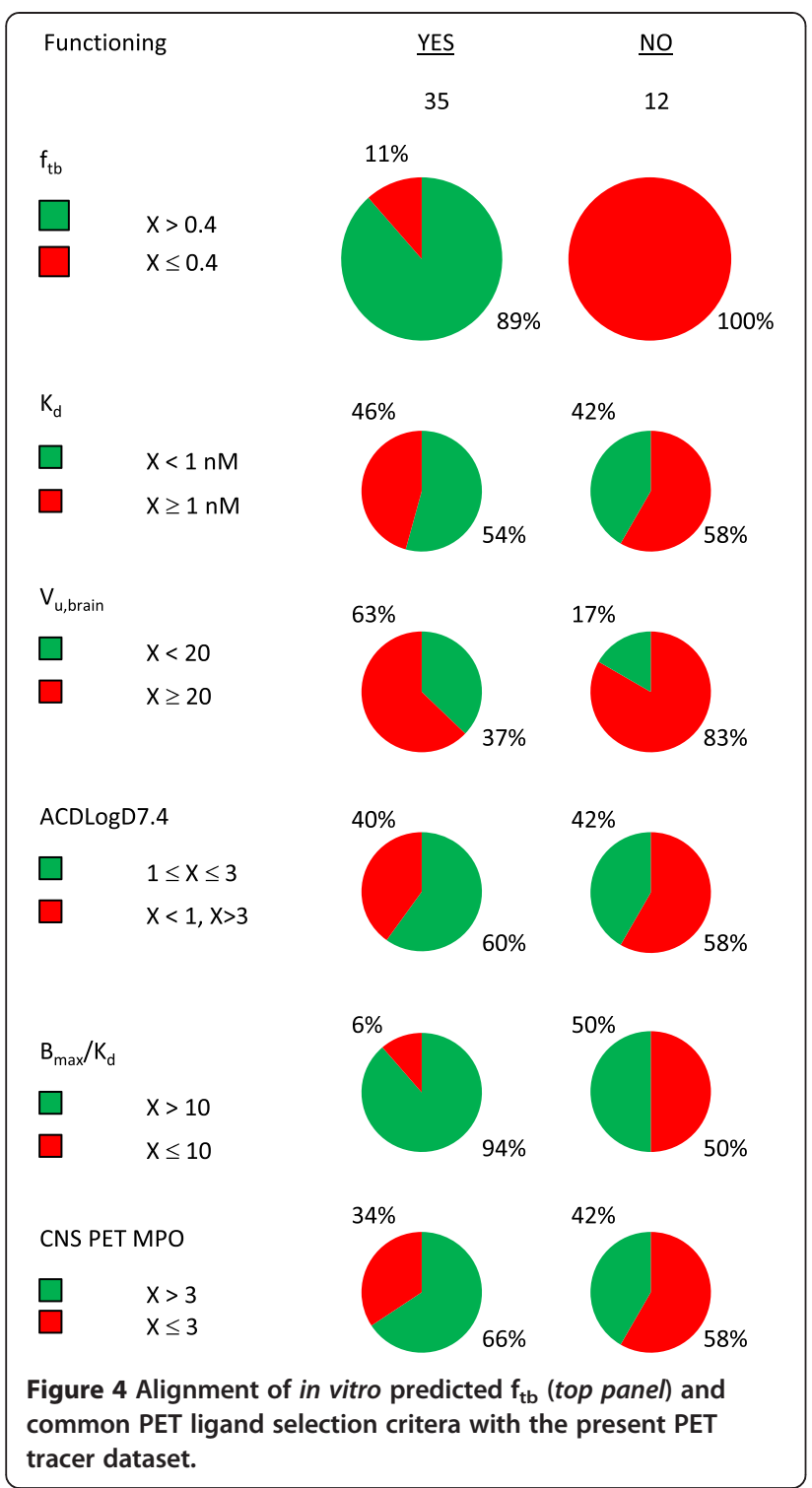

between predicted and observed $\mathrm{f}_{\mathrm{tb}}$ at a quantitative level. The deviation from perfect agreement, which is seen as scatter around the line of identity in Figure 3, is not marginal and represents a combined 'error' from several sources. Obviously, the simple model used for $\mathrm{f}_{\mathrm{tb}}$ (Eq. 3) may not always be sufficient to describe the full complexity of non-specific and specific binding as they occur in vivo. There is also considerable measurement-related error that is invariably associated with the approach taken in this study: to combine experimental data for typically three independent measurements/reports $\left(B_{\max }, K_{d}\right.$, and $\mathrm{V}_{\mathrm{u} \text {,brain }}$ ) and compare with a PET-derived value of $\mathrm{f}_{\mathrm{tb}}$, also carrying a measurement error. Considering that the accuracy of experimental methods such as those relating to $\mathrm{B}_{\max }, \mathrm{K}_{\mathrm{d}}$ and $\mathrm{V}_{\mathrm{u} \text {,brain }}$ are sometimes regarded as 'within 3 -fold'; it would seem that the predictions are no worse than should be expected from experimental error alone.
An illuminating example is $\left[{ }^{11} \mathrm{C}\right] \mathrm{DASB}$ for which the reported $K_{d}$ values ranged between 0.2 and $3.5 \mathrm{nM}$, corresponding to predicted $\mathrm{f}_{\mathrm{tb}}$ values between 0.86 to 0.26 . In this instance, the extreme value of $3.5 \mathrm{nM}$ was used for $K_{d}$ because it was the first encountered human value, despite the resulting in miss-classification as nonfunctioning. Another noteworthy example from this dataset is PK11195, which was misclassified by the model as non-functioning. Despite being a widely used marker for neuroinflammation, PK11195 binding in the brain has a relatively high non-specific component and was even designated as a non-functioning tracer by Zhang et al. in a recent publication [10]. In favor of the discriminating ability of the current model, the second generation TSPO radioligand PBR28 was ranked higher than PK11195. Nevertheless, PK11195 has some clinical utility, partly associated with its genotype aspecific binding, which should not be disregarded in this context.

It follows from the presented results that a default strategy at the outset of a tracer development campaign for a new target is to identify molecules with a combination of high affinity for the target and low non-specific binding, i.e. minimal values for the $\mathrm{K}_{\mathrm{d}} \times \mathrm{V}_{\mathrm{u} \text {,brain }}$ product. Depending on the density of the particular target $\left(\mathrm{B}_{\max }\right)$, different threshold values exist for $K_{d} \times V_{u \text {,brain }}$ to give rise to sufficiently high value of $\mathrm{f}_{\mathrm{tb}}$ and hence a functional PET tracer. This integrative approach contrasts with the traditional process for PET tracer identification, which has been based on benchmarking against a set of discrete criteria. Integration is evidently essential as no single criterion displays prediction sensitivity and specificity that are comparable to that of the $\mathrm{f}_{\mathrm{tb}}$ model. Furthermore, using all five analyzed criteria in Figure 4 as strict filters would result in the erroneous elimination of $86 \%$ of all functioning ligands; in fact, just two criteria $\left(\mathrm{V}_{\mathrm{u} \text {,brain }}<20 \mathrm{~mL} / \mathrm{g}\right.$ brain and $\operatorname{cog} \mathrm{D}$ of $\left.1-3\right)$ results in a $74 \%$ erroneous elimination. In the present dataset there is poor correlation between lipophilicity (ACDlogD7.4) and $\mathrm{V}_{\mathrm{u} \text {,brain }}$ (Figure 5), suggesting that lipophilicity should not be used to predict non-specific binding. Recently, a CNS PET MPO score was developed from a PET ligand dataset [10]. This score is a composite of various calculated molecular descriptors and therefore represents an interesting integration of molecular properties that could be used alongside experimentally predicted $f_{t b}$ or by itself to prioritize between new molecular structures before chemical synthesis is made.

A prerequisite for making in vitro predictions of $\mathrm{f}_{\mathrm{tb}}$ is access to reliable assays for experimental determination of $\mathrm{K}_{\mathrm{d}}, \mathrm{V}_{\mathrm{u} \text {,brain }}$, and $\mathrm{B}_{\max }$. At the stage of PET tracer development, there is almost always an assay available for the target: if not a binding assay yielding $\mathrm{K}_{\mathrm{d}}$ then at least a functional assay of potency $\left(\mathrm{EC}_{50}\right.$ or $\left.\mathrm{IC}_{50}\right)$. $\mathrm{V}_{\mathrm{u} \text {,brain }}$ is best measured in vitro using the high-throughput brain slice 


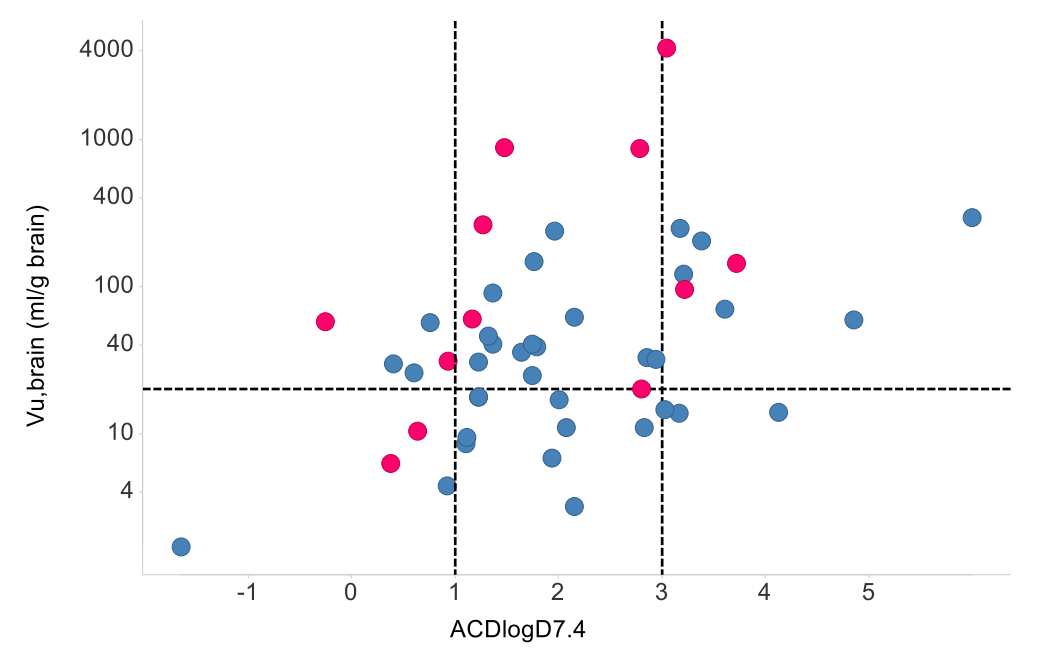

Figure 5 Lack of close correlation between ACDlogD7.4 and $\mathrm{V}_{\mathrm{u} \text {,brain }}$ for the functioning (blue) and non-functioning (red) PET tracers. Dashed lines represent commonly applied PET-ligand selection criteria; vertical lines border the desired range of lipophilicity, and the horizontal line indicates the maximum level of non-specific binding.

methodology [11]. However, for the present integrated approach it may be sufficient to use the more readily available equilibrium dialysis brain homogenate binding assay and apply correction factors on the basis of drug $\mathrm{pK}_{\mathrm{a}}$ [12]. Determination of $\mathrm{B}_{\max }$ can pose a significant challenge since it generally requires a suitable in vitro radioligand. However, regardless of the $B_{\max }$ value, the initial objective of tracer optimization can be to minimize the $\mathrm{K}_{\mathrm{d}} \times \mathrm{V}_{\mathrm{u} \text {,brain }}$ product, even though the target level is not defined. If the target $B_{\max }$ is determined or known beforehand, the $\mathrm{f}_{\mathrm{tb}}$ prediction model can be used not only to rank-order tracer candidates but also to assess the likelihood of being successful in identifying a tracer for a particular target. Furthermore, it is our experience that it is useful to determine $B_{\max }$ both in the preclinical species and human to facilitate the translation of $\mathrm{f}_{\mathrm{tb}}$ and thereby reduce the risk of attrition.

The presented approach does not specifically address the effects of drug efflux at the blood-brain barrier or the impact of tracer metabolites in the brain, yet it predicts the present dataset with good precision and accuracy. It is possible that there is a selection bias in the dataset owing to the fact that a majority of tracers are either CNS drugs, established functioning tracers, or both. Therefore, $\mathrm{f}_{\mathrm{tb}}$ predictions should be supplemented with predictions of CNS exposure using in vivo, in vitro, or in silico techniques. Prediction of the level of tracer metabolites in the brain is not straightforward; however, it appears to not deteriorate the predictive value of the model, which is consistent with metabolites generally having more hydrogen bond acceptors and therefore increased probability of being effluxed at the blood-brain barrier. In summary, we recognize that a poor ratio of specific to non-specific binding is one of the primary reasons for attrition in PET-tracer development and we expect this to be managed with $\mathrm{f}_{\mathrm{tb}}$ predictions.

\section{Conclusions}

A mechanistically integrated method for the identification of CNS tracer candidates was developed in which the non-specific binding, tracer affinity, and the target protein expression in the brain were taken into account. The method is rapid and accurate and is expected to facilitate the development of novel PET tracers for the molecular imaging community.

\section{Additional files}

Additional file 1: CNS PET tracer dataset.

Additional file 2: Derivation of target-bound fraction using PET nomenclature.

Additional file 3: Tracer evaluation template.

\section{Abbreviations}

$\mathrm{B}_{\text {max: }}$ target density; $\mathrm{BP}_{\mathrm{ND}}$ : non-displaceable binding potential; $\mathrm{C}_{\mathrm{u}}$ brainsf: concentration of unbound ligand in brain interstitial fluid; $\mathrm{f}_{\mathrm{tb}}$ : target-bound fraction of tracer; $f_{u, b r a i n}$ : unbound fraction in brain homogenate; $\mathrm{K}_{\mathrm{d}}$ : ligand affinity to target protein; MPO: multiparameter optimization; PET: positron emission tomography; $V_{u, b r a i n}$ : unbound volume of distribution in the brain.

\section{Competing interests}

The authors declare that they have no competing interests.

\section{Authors' contributions}

Contributions to the conception of the study and its design were made by MF, MW, MA, LF, and MS. MS-S carried out brain slice experiments. MF and MS conducted the literature review and drafted the manuscript together with LF. All authors read and approved the final manuscript. 


\section{Acknowledgements}

The authors thank Ingela Ahlstedt, Anudharan Balendran, Gunilla Jerndal, Marie Johansson, and Petter Svanberg for helpful discussions and participation in generation of brain slice data.

\section{Author details}

${ }^{1}$ Respiratory Inflammation and Autoimmunity Innovative Medicines, AstraZeneca R\&D, Mölndal, Sweden. ${ }^{2}$ Translational PKPD, Department of Pharmaceutical Biosciences, Uppsala University, Uppsala, Sweden. ${ }^{3}$ Cardiovascular and Metabolic Diseases Innovative Medicines, AstraZeneca R\&D, Mölndal, Sweden. ${ }^{4}$ CNS \& Pain Innovative Medicines, AstraZeneca R\&D, Södertälje, Sweden. ${ }^{5}$ AstraZeneca Translational Science Centre, Department of Clinical Neuroscience, Karolinska Institutet, Stockholm, Sweden.

Received: 4 July 2014 Accepted: 7 September 2014

Published online: 23 September 2014

\section{References}

1. Pike W: PET radiotracers: crossing the blood-brain barrier and surviving metabolism. Trends Pharmacol Sci 2009, 30:431-440.

2. Halldin C, Gulyas B, Langer O, Farde L: Brain radioligands-state of the art and new trends. Q J Nucl Med 2001, 45:139-152.

3. Cunningham VJ, Parker CA, Rabiner EA, Gee AD, Gunn RN: PET studies in drug development: methodological considerations. Drug Discov Today 2005, 2:311-315.

4. Waterhouse RN: Determination of lipophilicity and its use as a predictor of blood-brain barrier penetration of molecular imaging agents. Mol Imaging Biol 2003, 5:376-389.

5. Patel S, Gibson R: In vivo site-directed radiotracers: a mini-review. Nucl Med Biol 2008, 35:805-815.

6. Rosso L, Gee AD, Gould IR: Ab initio computational study of positron emission tomography ligands interacting with lipid molecule for the prediction of nonspecific binding. J Comput Chem 2008, 29:2397-2405.

7. Jiang Z, Reilly J, Everatt B, Briard E: A rapid vesicle electrokinetic chromatography method for the in vitro prediction of non-specific binding for potential PET ligands. J Pharm Biomed Anal 2011, 54:722-729.

8. Guo Q, Brady M, Gunn RN: A biomathematical modeling approach to central nervous system radioligand discovery and development. J Nucl Med 2009, 50:1715-1723.

9. Guo Q, Owen DR, Rabiner EA, Turkheimer FE, Gunn RN: Identifying improved TSPO PET imaging probes through biomathematics: the impact of multiple TSPO binding sites in vivo. Neuroimage 2012, 60:902-910.

10. Zhang L, Villalobos A, Beck EM, Bocan T, Chappie TA, Chen L, Grimwood S, Heck SD, Helal CJ, Hou X, Humphrey JM, Lu J, Skaddan MB, McCarthy TJ, Verhoest PR, Wager TT, Zasadny K: Design and selection parameters to accelerate the discovery of novel central nervous system positron emission tomography (PET) ligands and their application in the development of a novel phosphodiesterase 2A PET ligand. J Med Chem 2013, 56:4568-4579.

11. Friden $M$, Ducrozet $F$, Antonsson $M$, Middleton $B$, Bredberg $U$ Hammarlund-Udenaes M: Development of a high-throughput brain slice method for studying drug distribution in the CNS. Drug Metab Dispos 2009, 37:1226

12. Friden $M$, Bergstrom $F$, Wan $H$, Rehngren M, Ahlin G, Hammarlund-Udenaes $M$, Bredberg U: Measurement of unbound drug exposure in brain: modeling of $\mathrm{pH}$ partitioning explains diverging results between the brain slice and brain homogenate methods. Drug Metab Dispos 2011, 39:353-362.

13. Innis RB, Cunningham VJ, Delforge J, Fujita M, Gjedde A, Gunn RN, Holden J, Houle S, Huang SC, Ichise M, lida H, Ito H, Kimura Y, Koeppe RA, Knudsen GM, Knuuti J, Lammertsma AA, Laruelle M, Logan J, Maguire RP, Mintun MA, Morris ED, Parsey R, Price JC, Slifstein M, Sossi V, Suhara T, Votaw JR, Wong DF, Carson RE: Consensus nomenclature for in vivo imaging of reversibly binding radioligands. J Cereb Blood Flow Metable 2007, 27:1533-1539.
14. Hammarlund-Udenaes M, Friden M, Syvanen S, Gupta A: On the rate and extent of drug delivery to the brain. Pharm Res 2008, 25:1737-1750.

15. Farde L, Eriksson L, Blomquist G, Halldin C: Kinetic analysis of central [IIC] Raclopride binding to D2-dopamine receptors studied by PET-a comparison to the equilibrium analysis. J Cereb Blood Flow Metable 1989, 9:696-708.

doi:10.1186/s13550-014-0050-6

Cite this article as: Fridén et al:: Identification of positron emission tomography (PET) tracer candidates by prediction of the target-bound fraction in the brain. EJNMMI Research 2014 4:50.

\section{Submit your manuscript to a SpringerOpen ${ }^{\odot}$ journal and benefit from:}

- Convenient online submission

- Rigorous peer review

- Immediate publication on acceptance

- Open access: articles freely available online

- High visibility within the field

- Retaining the copyright to your article

Submit your next manuscript at $>$ springeropen.com 